\title{
Assessing the Reliability of Bus Transportation System in Pune Municipal Corporation
}

\author{
Ninad Chandrayan
}

Urban Planner, Pune-411052, India

\begin{abstract}
Improving the reliability of bus service can increase the desirability of public transportation to current and future riders. An understanding of service reliability is necessary to develop strategies, which helps transport organizations provide better services. The study area selected is Pune Municipal Corporation. Pune is one of the cities in India, situated in the state of Maharashtra. It is the eighth largest metropolitan city in India with the population of 3.1 million and the population density of 12770 person per sq.km. In the last 10 years there has been a rapid rise in the mobility pattern of people and a remarkable growth in the number of vehicles in pune city especially Two-wheelers and Four wheelers because of improved quality of life and rise in income level of the people. Despite these problems, the organization handling the operation of Bus transport system has been unsuccessful in improving the service of the bus. Every commuter wants a reliable mode of public transport. However, due to lack of quality and inadequate public transport system, people are using personalized vehicles, which is not only creating the problem of traffic congestion but also increasing the chances of fatalities and environmental issues. The study aims at assessing the performance parameters of bus transportation system in pune and to measure the reliability index. It involves assessment of accessibility of buses in Pune, the operational characteristics of the bus system and to identify and study the performance parameters, which affects the reliability of the bus system in Pune.
\end{abstract}

Keywords: Reliability, Punctuality, Comfortability, Load-factor.

\section{Introduction}

\subsection{Background}

Enhancing the reliability of Bus transport system can possibly expand the appeal of open transportation to present and future riders. A comprehension of System's reliability is important to create techniques, which would help transport associations give better administrations. The review territory chosen is Pune city. The review goes for evaluating the execution and to quantify the unwavering quality list of Bus Transportation System in Pune. It includes appraisal of openness of transports in Pune, the operational attributes of the transport framework and to distinguish and concentrate on the execution parameters, which influences the unwavering quality of the transport framework in Pune. Reliability of Public Transport systems have been considered critically important by most public transport users because passengers are adversely affected by the outcome associated with unreliability such as additional waiting time, late or early arrival at destinations and missed connections, which increases their anxiety and discomfort. Reliability has also been identified as an important factor in determining the mode choice. Therefore, the unreliability in Public Transport drives away the existing and prospective passengers

\subsection{Factors affecting the reliability}

Many factors contribute to bus unreliability, day-to-day and within-day variability in traffic flow and congestion level cause delays and make prediction of bus journey time uncertain, excess passenger demand cause longer dwell time at bus stops, buses do not always run on schedule, or appear in bunches, operators have insufficient spare capacity to cover for service breakdowns etc. The factors affecting reliability can be classified into the following:
- Traffic Characteristics: Traffic Characteristics such as traffic congestion, day-to-day and within-day variation in travel demand and traffic congestion levels.

- Route Characteristics: Route characteristics such as the length of the route, number of lanes, location of the busstops, Provision of the bus lanes whether in short stretches or all along route, number of intersections. On street parking, number of stops on the route, volume of passenger activity, seasonality, time of day, direction of travel, driver behavior also has an impact on the bus running time and hence it affects the reliability.

- Passenger Characteristics: It includes passenger volume at stops, variability in passenger volume, passenger route choice, passenger arrival distribution. Factors such as passenger demand, link travel time variability and the service frequency may cause buses to bunch on a route, thus affecting the service reliability.

- Operational Characteristics: It includes scheduling system, staff shortages, fleet availability, fleet maintenance, ticketing system, and variability in driver behavior. Poor maintenance of the fleet and staff shortages result in poor level of service and reliability.

\subsection{Introduction to Pune city}

Pune is one of the cities in India, situated in the state of Maharashtra. It is the eighth largest metropolitan city in India with the population of 3.1 million and the population density of 12770 people per sq.km. Pune Municipal Corporation (PMC) covers up to an area of $243.84 \mathrm{sq}$. km. housing 2.54 million populace within 144 wards. Pune as a rapidly growing contemporary industrial center after independence, and today identified as a growing metropolis. Pune, also recognized as an 'Oxford of India', houses six Universities with about 600 functional higher education centers catering to an estimated 5-lakh student population. Pune Municipal Corporation has a population of 3 million (census 2011)

Volume 6 Issue 12, December 2017 


\section{International Journal of Science and Research (IJSR) \\ ISSN (Online): 2319-7064}

Index Copernicus Value (2016): 79.57 | Impact Factor (2015): 6.391

Migration has increased from 3.7 Lakhs in 2001 to 6.6 Lakhs in 2011. The population density has increased from 10405.28 person per Sq.km in 2001 to $12,770.25$ person per Sq.km. Population density especially in the core areas are very high.

\subsection{Earlier planning efforts in Pune}

Town Planning Schemes: Immediately after the introduction of the Bombay Town Planning Act of 1915, the then Poona City Municipality took steps to control the development of the growing town on the west and the north of the City by undertaking a Town Planning Schemes. T.P.S.No.1. Bhamburda, which finalized in the year 1931. It had followed by three more schemes, viz. Town Planning Scheme No. III of Parvati and Gultekdi, Town Planning Scheme No. II of Somwar-Mangalwar Peth and T.P.S. Sangamwadi which was lately undertaken by P.M.C. Prior to the merger of suburban Municipality in PMC, the then suburban Municipality undertook T.P.S. Pune suburban No.1 which was finalized in 1930. These Schemes included most of the remaining areas on the southern and eastern parts of the City, which were open. In addition to these Town Planning Schemes, subsequently 2 T.P.S. mainly for industrial development were taken in the eastern part of the city viz. in Hadapsar area.

Other planning schemes undertaken and developed by PMC In addition to all the TPS

1) Scheme of Tilak road running from Swargate to Lakdi Bridge (Sambhaji Bridge)

2) Scheme of Laxmi road running from Lakdi Bridge to Quarter Gate through the heart of the town. This was an east-west road.

3) Ganesh Road Scheme, which joined the Jijamata Baug to the Phadke Howd.

4) Phule Market Road from Phule Market to the Govind Halwai Chowk.

5) Bajirao Road from Parvati Naka to Vishrambaug Wada.

6) Mankeshwar Road from Ram baug to Omkareshwar.

7) In addition, the PMC also undertook work of shifting of Timber market from Gultekadi to presently located timber market in Bhavani Peth. This is an ambitious scheme implemented in the outer area. The present timber market is an area planned for building material business. The Pune Municipality had thus not only controlled the development of the out-laying open areas butal so provided new avenues for traffic and development in the city. This development had proceeded on the systematic lines of urban development.

8) The old city of Pune was however very congested and despite the development of new roads and road widening schemes, it was realized that the town proper could not be improved to the standards laid down in the Town Planning norms or to those standards which were followed in the schemes of Town Planning which were in hands at that time. The Municipality had prescribed regular lines of streets for practically all the roads in old city. This partially regulated the construction of buildings.

\section{Literature Study}

In the past few years, some studies have been conducted to determine bus service reliability using measures of on-time performance, headway or headway adherence between buses, bus running time, run time variation or excess waiting time. Given below re some of the reviews-

\subsection{A simulation based reliability assessment approach for congested transit network, (Yin, 2004)}

To assess transit service reliability, taking into account the interaction between the network performance and passengers' route choice behavior, Yin developed a generic simulationbased approach. Three types of the reliability were defined from perspectives of the community or transit administration, the operator, and passengers, namely:

- System wide travel time reliability

- Schedule reliability

- Direct boarding waiting-time reliability

2.2 Federal Transit Administration, Transit Cooperative research program and Transit Development Cooperation, (Kittelson \& Associates, 2003)

In this, On-time performance and headway adherence, the most widely used reliability measures in the transit industry, were discussed. The on-time performance LOS (i.e., Level of Service) and headway adherence LOS were provided in this manual. Later, Camus et al. (2005) discussed the advantages and limitations of the TCQSM methods for the estimation of the reliability LOS, based on automated vehicle location (AVL) data collected in Trieste, Italy. A new performance measure called weighted delay index was proposed, allowing the amount of delay, the effect of early departures on users, and a flexible tolerance to be considered. This allowed the limitations of the TCQSM to be overcome.

\subsection{Empirical analysis of bus transit on-time performance (Strathman J.D, 1993):}

In this, Strathman presented an empirical assessment of factors affecting the on-time performance of the fixed route bus system in Portland, Oregon. A multinomial logit model relating early, late, and on-time bus arrivals to route, schedule, driver, and operating characteristics was developed and estimated. The model results showed that the probability of on-time failures increased during PM peak periods, with longer headways and higher levels of passenger activity, and as buses progress further along their routes. Part-time drivers were also more likely to fall behind the schedule. With few exceptions, schedule changes and operations-control actions could mitigate these effects.

\subsection{Factors affecting running time in transit routes, (Abkowitz M.D. 1983):}

In this, Abkowitz studied factors affecting the running time on transit routes and methods for maintaining transit service regularity. These studies reported on estimating empirical models of transit mean running time and identifying 


\section{International Journal of Science and Research (IJSR) \\ ISSN (Online): 2319-7064}

Index Copernicus Value (2016): 79.57 | Impact Factor (2015): 6.391

operations-control actions to improve reliability. It was found that mean running time is strongly influenced by trip distance, people boarding and alighting, and signalized intersections. The proposed method for maintaining service regularity through improved scheduling and real-time control was found to be a reasonable solution. It was suggested that improvements of reliability may be possible through planning shorter routes or adopting investment strategies which emphasize improved control rather than modification of existing link characteristics.

\subsection{Factors affecting the reliability of Urban Bus services (Sterman, 1976)}

In this, it was observed that the reliability of bus transit degraded when the distance between Origin and destination increased (i.e.) the reliability decreased when route length increased. More the longer routes, more will the intensity of intersection control, traffic volumes, and, with less certainty, bus passenger loadings. Hence, several strategies, such as decreasing the route length, intensity of intersection control and traffic volumes, were suggested to increase the urban bus transit reliability.

The studies identified in the literature review have offered insights into bus service reliability and the factors contributing to the bus service variability. They suggested that the on time/punctuality performance and headway evenness are primary focuses in the practice of bus reliability analysis. However, most of the studies reviewed primarily relied upon analyzing one or several transit routes and the performance parameters' lack of necessary correlation. Little effort has been made to explore bus reliability assessment on a large-scale network and investigate the relationship between different performance parameters for bus reliability.

\section{Transit Network in Study area}

The transit network represents the connectivity, headways, speed and accessibility of transit services. Pune's bus transport system is specified as that using the transport linkage and having bus stops at specified location.

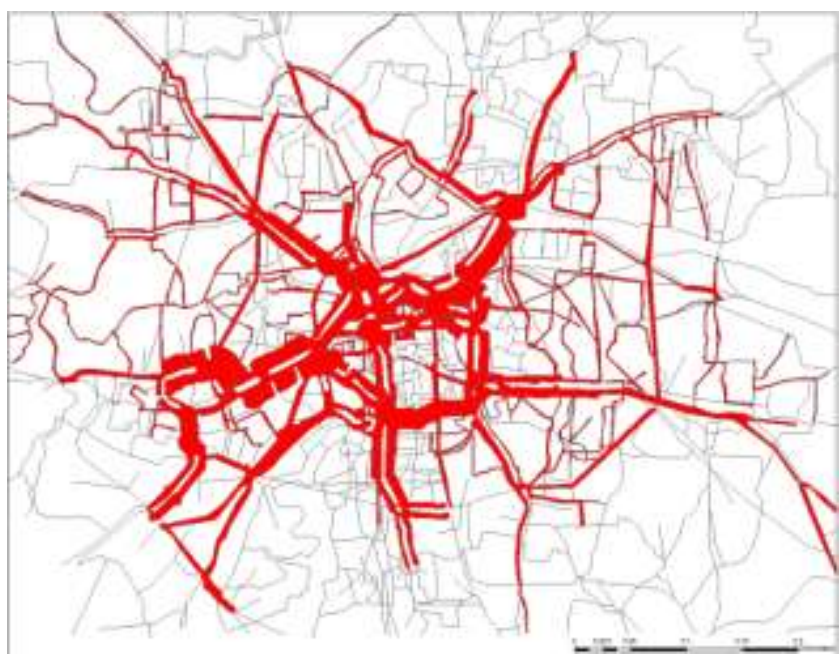

Figure 1: Bus route density map of Pune Municipal Corporation
Presently, about 390 bus routes are operated in Pune Municipal Corporation with the total fleet of 2022 buses. Information was collected and coded into the system. Frequency for each of the bus services is also included.

\subsection{Routes designated for study}

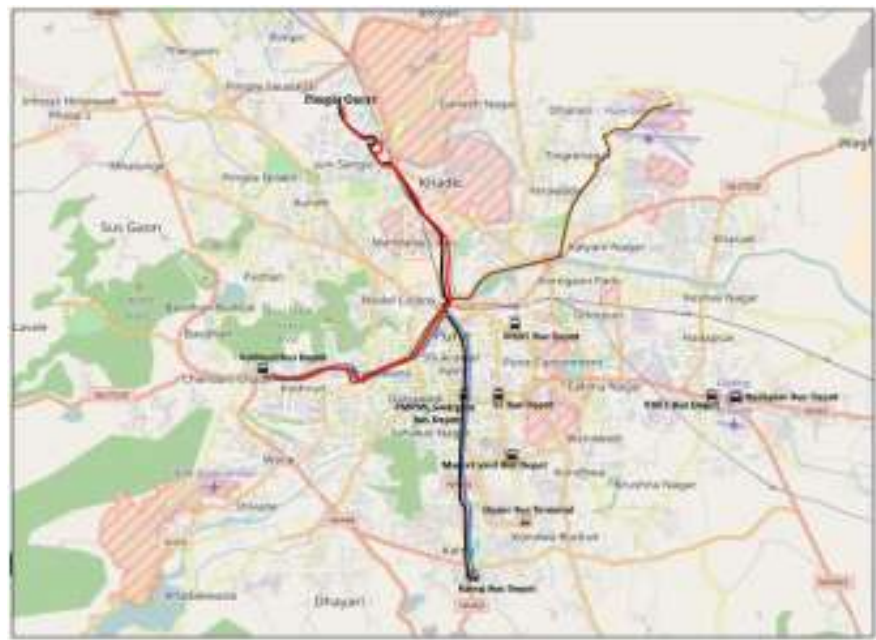

Figure 2: Bus route designated for study

Selection of routes to assess the performance of Bus Transport System has been carried out on 4 major bus routes on the basis of initial pilot study. On board Origin and Destination Survey, Speed and Delay survey has been done on the following four routes:

Table 1: Route details of PMPML buses in PMC

\begin{tabular}{|c|c|c|c|c|}
\hline Route & Start & End & $\begin{array}{c}\text { Total Bus } \\
\text { Stops }\end{array}$ & $\begin{array}{c}\text { Total Distance } \\
\text { (in Kilometer) }\end{array}$ \\
\hline $11 \mathrm{k}$ & Katraj Bus Depot & Pimple Gurav & 45 & 23 \\
\hline 95 & $\begin{array}{c}\text { Kothrud Bus } \\
\text { Depot }\end{array}$ & Pimple Gurav & 51 & 26 \\
\hline 102 & $\begin{array}{c}\text { Kothrud Bus } \\
\text { Depot }\end{array}$ & Loahgoan & 46 & 23 \\
\hline 103 & $\begin{array}{c}\text { Kothrud Bus } \\
\text { Depot }\end{array}$ & $\begin{array}{c}\text { Katraj Bus } \\
\text { Depot }\end{array}$ & 35 & 19 \\
\hline
\end{tabular}

\section{Data Analysis}

Primary as well as secondary data was collected during the survey carried out in Pune Municipal Corporation. For studying the reliability index of Bus Transportation system in the study area, two main factors were taken into consideration-

1) Performance Parameter of Bus Transportation System.

2) Operational Characteristics of Bus Transportation System.

\subsection{Performance Parameter}

Performance parameter deals with the daily performance of bus in terms of:

- Speed

- Boarding and Alighting $\}$ the Punctuality factor

- Punctuality (Actual and Schedule

- Passenger Accumulation J Mainly used to assess

- Load Factor

Volume 6 Issue 12, December 2017 www.ijsr.net 


\section{International Journal of Science and Research (IJSR) \\ ISSN (Online): 2319-7064}

Index Copernicus Value (2016): 79.57 | Impact Factor (2015): 6.391

\subsection{Operational Characteristics}

Operational Characteristics play a major role in assessing the reliability of Bus Transportation System. Service provided by the organization (Pune Mahanagar Parivahan Mahamandal Limited) assessed and the information and data was collected from the office. Operational Characteristics mainly include:

- Accessibility

- Safety

- Comfortability

- Frequency

- Total Bus Fleet (Daily Out shedding)

\section{Survey Findings}

\subsection{Accessibility}

In Pune Municipal Corporation, Bus serves as the main mode of Public Transportation, but still, it finds difficult to attract commuters because of its inaccessibility. Following map shows the Bus Network accessibility of Pune Municipal Corporation:

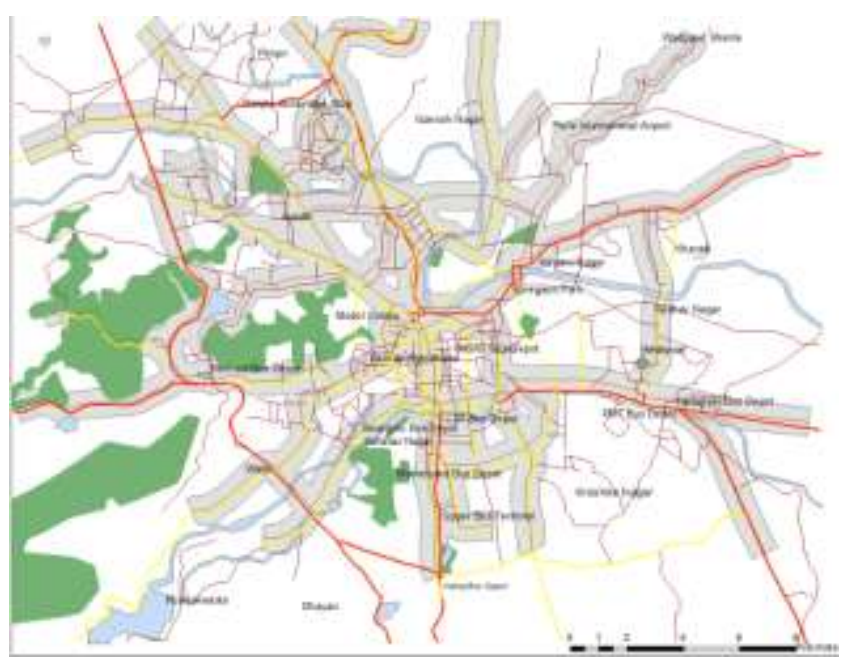

Figure 3: Bus network accessibility of Pune Municipal Corporation

The total area of Pune Municipal Corporation is $430 \mathrm{~km} . \mathrm{sq}$. within which 390 routes intersect and overlap each other. On the total number of routes, there are about 1320 number of bus stops. On an average, there are proximately 4 bus stops per route. By taking into consideration the average bus stops on each route and the total number of bus stops, we get the area of 330 sq.km. Each bus stop has the influence area of 500 meters. Therefore, the total area under influence is 0.78 sq.km. By taking the total number of bus stops and total influence area into consideration, we get the total accessibility of 1029 sq. km. By taking the total area of Pune Municipal Corporation and the area of average number of bus stops, we get the total accessibility of $77 \%$. That means $23 \%$ of the area is inaccessible by Bus Transport System.

\subsection{Safety}

Safety is one of the main factor when it comes to Characteristics of Good Public Transportation of any city. People mainly decide whether to commute by bus or not depends on its safety. To conclude whether the bus is safe to commute or not is dependent on the following factors:

\section{- Bus Fleet Age}

Bus fleet age plays key role in recognizing the safety of the Bus Transportation System, more the age of the bus, more will be the chances of Breakdown or accidents. Breakdown of the bus also affect the reliability of the system as breakdown result in late arrival of the bus to destination, which diverts commuters to travel by private vehicles. In addition, old buses consume more diesel, and harm environment due to excess amount of pollution.

Following table shows the Age-wise description of buses in Pune Municipal Corporation:

Table 2(a): Route details of PMPML buses in PMC

\begin{tabular}{|c|c|c|}
\hline Model & No. of buses & Age \\
\hline 2000 & 23 & 17 \\
\hline 2003 & 69 & 14 \\
\hline 2004 & 105 & 13 \\
\hline 2005 & 127 & 12 \\
\hline 2006 & 05 & 11 \\
\hline 2007 & 215 & 10 \\
\hline 2008 & 130 & 09 \\
\hline 2009 & 197 & 08 \\
\hline Total & $\mathbf{8 7 1}$ & \\
\hline
\end{tabular}

Table 2(b): Route details of PMPML buses in PMC

\begin{tabular}{|c|c|}
\hline Year(s) & No. of Buses \\
\hline $0-5$ & 280 \\
\hline $6-10$ & 793 \\
\hline $11-12$ & 132 \\
\hline More than 12 years & 197 \\
\hline Total & 1402 \\
\hline
\end{tabular}

\section{- Bus Replacement Policy:}

Bus Replacement Policy is a term, which deals with replacement of old and broken buses with new buses. As far as Bus transportation safety is concern, more old the bus, more are the chances of its accidents and breakdown. Therefore, there are some guidelines of Bus Replacement Policy followed. Now, as per the Bus Replacement Policy of Central Institute of Road Transport, any bus that is 8 years or above should be replaced. As shown in Table.2 (a) and Table. 2 (b) the average age of bus in Pune Municipal Corporation is 8 Years 3 Months 3 Days. Out of the total number of buses in Pune Municipal Corporation, about $\mathbf{6 2 \%}$ of buses are above the age limit. As a result, these buses are unsafe to drive since the chances of accident increases and unfit to commute due to chances of bus breakdown. Frequent breakdown of buses also adds traffic jam.

In addition, when it comes to passenger's safety inside the bus, it was observed that windows of several buses were jammed or broken. Holding bars, which are necessary for standing commuters were missing in several old buses, Seats were not comfortable and many commuters mostly avoid to sit on last seats as they said that the bus jumped on speed breakers so dangerously that it could claim the life of commuters. Certain safety equipment like fire extinguisher, first aid Kits were missing in several buses.

\section{Volume 6 Issue 12, December 2017}




\section{International Journal of Science and Research (IJSR) \\ ISSN (Online): 2319-7064}

Index Copernicus Value (2016): 79.57 | Impact Factor (2015): 6.391

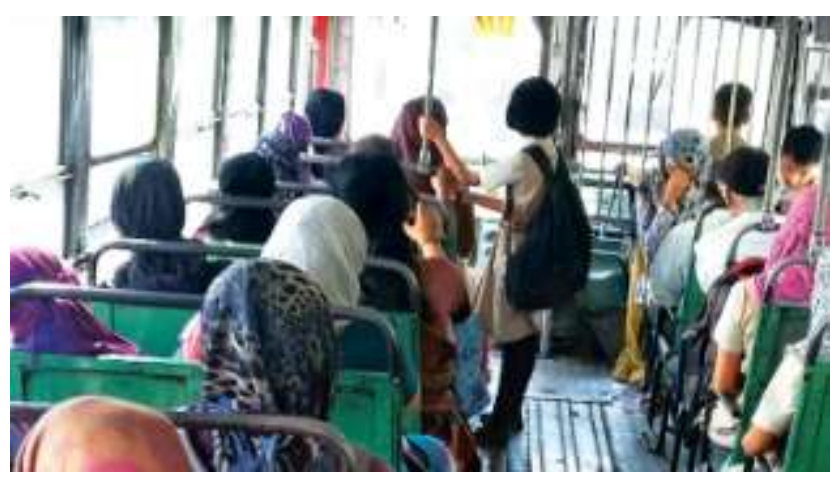

Figure 4: Holding bars are missing

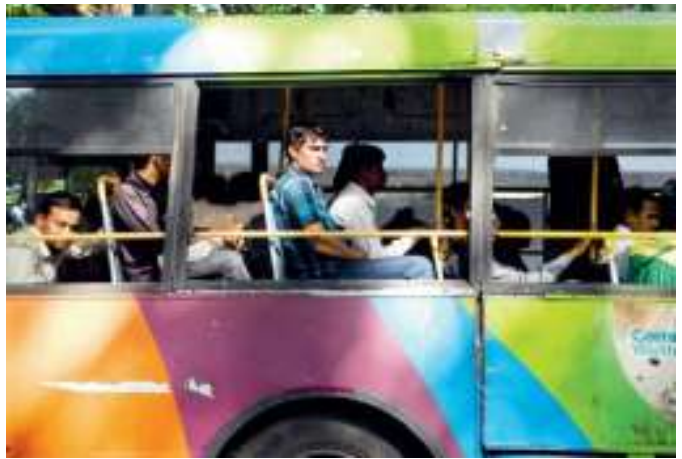

Figure 5: Windows of PMPML bus broken

\section{- Monthly Breakdown}

Breakdown of the bus mostly depends on the age of the bus. As the age of the bus increases, the chances of breakdown of the bus also increases. Breakdown affects the reliability of the bus system as breakdown results in either cancellation or late arrival of the bus to its scheduled destination, which diverts commuters to travel by private vehicles.

- Cancellation of Kilometers due to breakdown or accidents9.1\% (12778)

- Breakdown rate- 0.43 for 10000 kilometers

- Cancellation of buses due to breakdown or accidents per month- 656

\subsection{Comfortability}

Comfortability in bus is measured in terms of Passenger Accumulation and Load Factor. The passenger density within the bus can be termed as passenger accumulation. Usually, the passenger density increases as the journey from origin to destination progresses or Vice-a-Versa. Passenger Accumulation and Load Factor is co-related as the accumulation in bus increases, the load factor increases. As the load factor increases, the comfortability decreases. Load Factor of any bus also depends on the capacity of the bus and hence it is further calculated as

Load Factor $=\frac{\text { Passenger } \text { Accumulation }}{\text { Total capacity of Bus }}$

\section{- Load Factor:}

General Observation: Compared to four routes taken for study, route no. 103 is the shortest with the total distance of 18 kilometers. During the field survey conducted in the first shift, it was observed that the load factor on route 103 was more as compared to other three routes. The total capacity of bus is 33 sitting and 17 standing. During the field survey conducted in the second shift, load factor of route $11 \mathrm{k}$ was highest until Ruby hall. There was a sudden decline in the load factor of route $11 \mathrm{k}$ from pune station. During the field survey conducted in the third shift, load factor of route $11 \mathrm{k}$ and route 103 was highest. Graph shows that load factor of route $11 \mathrm{k}$ was high during origin and started falling as the journey progressed. For route 103, Graph shows that load factor was low during origin and started rising as the journey progressed but again declined as the journey reached its destination.
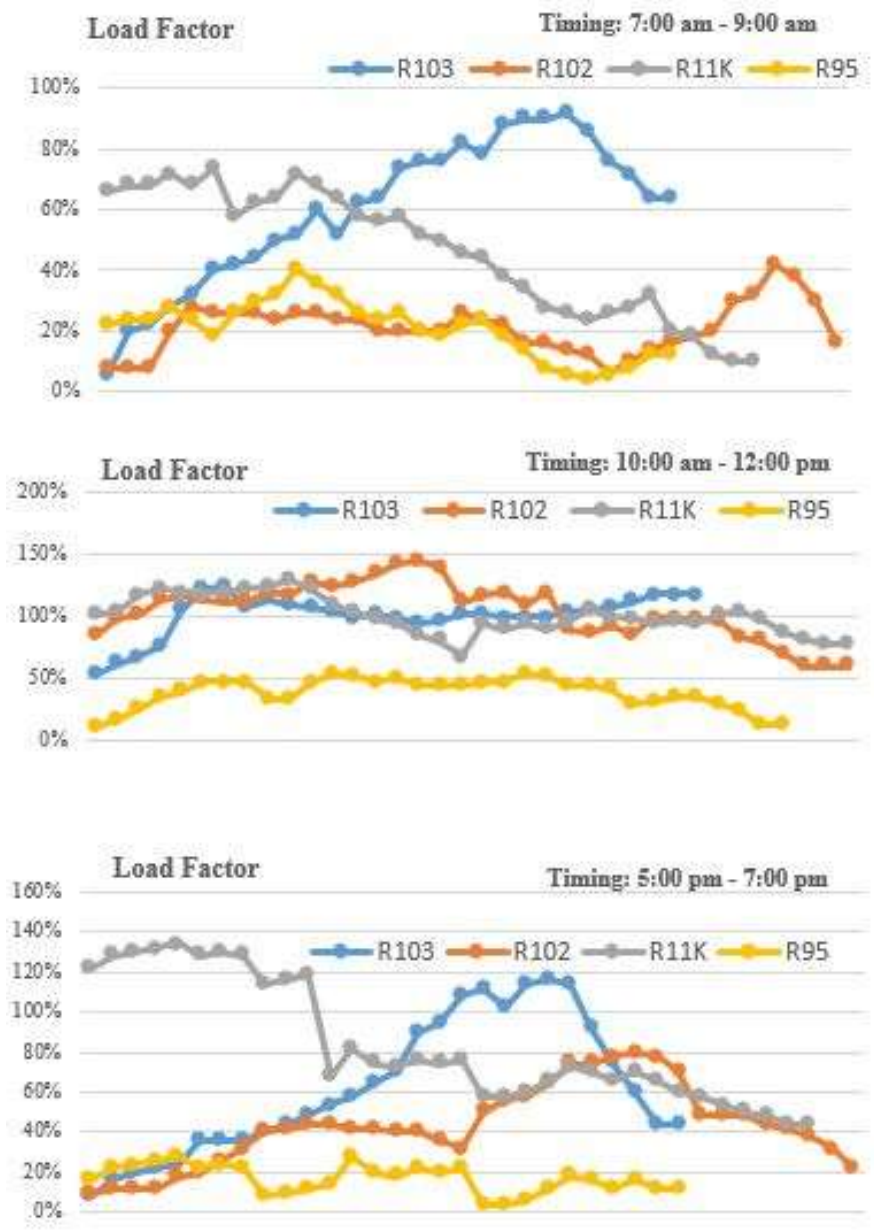

Figure 6: Load factor of routes, graphical representation

\section{- Passenger Accumulation}

General Observation: During the first shift of survey, passenger accumulation on route no 103 was highest as compared to other three routes. Maximum passenger accumulation on R103 was 46 and lowest was 3. Maximum passenger accumulation on R11k was 37 and lowest was 5 . Maximum passenger accumulation on R95 was 20 and lowest was 2, whereas, for R102, the maximum accumulation was 21 and lowest was 4. During the second shift of survey, passenger accumulation on R102 was highest as compared to other three routes. Maximum passenger accumulation on R102 was 71 and lowest was 30. Maximum passenger accumulation on R11k was 65 and lowest was 34. Maximum passenger accumulation on R95 was 38 and lowest was 8 , whereas, for R103, the maximum accumulation was 62 and lowest was 29

\section{Volume 6 Issue 12, December 2017}




\section{International Journal of Science and Research (IJSR) ISSN (Online): 2319-7064}

Index Copernicus Value (2016): 79.57 | Impact Factor (2015): 6.391
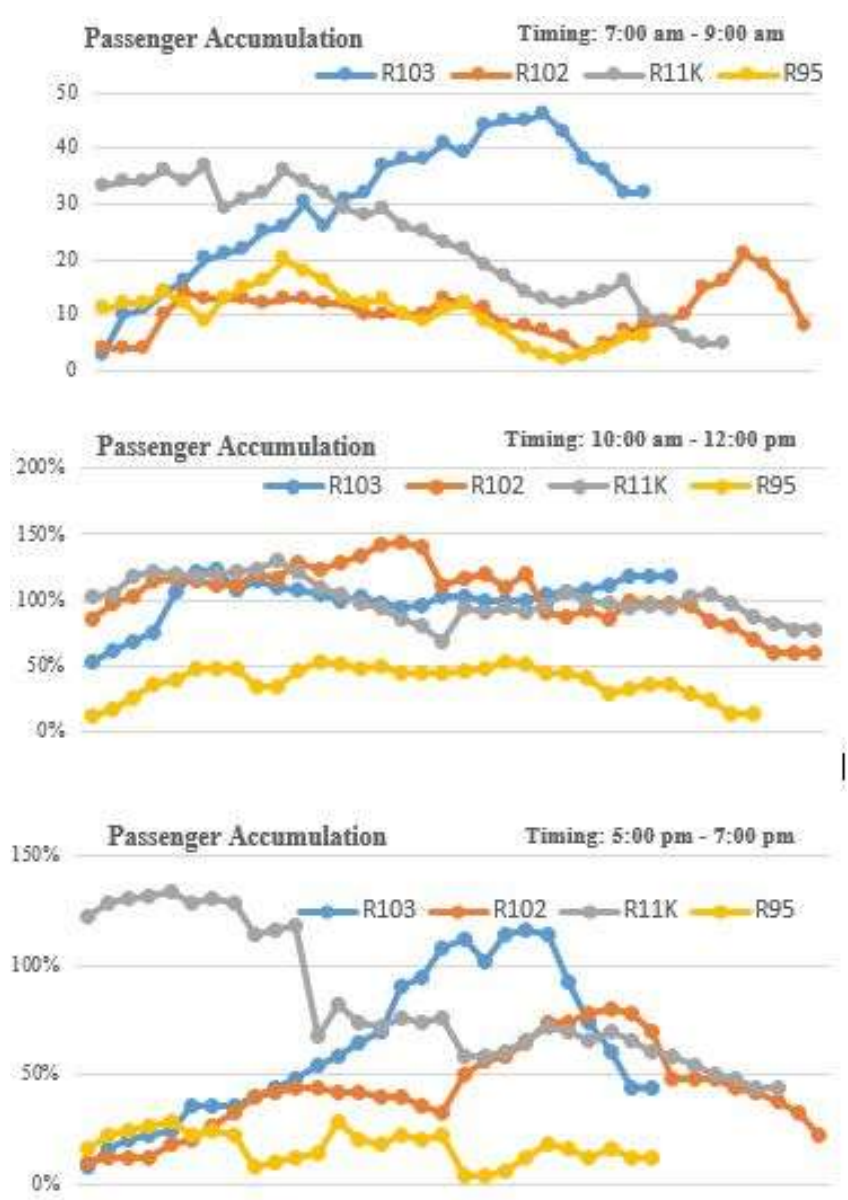

Figure 7: Passenger Accumulation of routes, graphical representation

\section{Conclusion}

Bus service reliability is one of the key factors in the accessibility of bus services because "arriving when planned" is one of the most important desires of commuters. The assessment of transit system reliability and efficiency has attracted considerable attention in the literature because the vast display of useful and important policy results can be extracted from such an analysis. In this thesis, we used three performance parameters on bus service reliability, employing sampling survey techniques to estimate service reliability at stop, route and network levels.

Using the bus transport system in Pune as a case study and considering the operational characteristics of Pune Mahanagar Parivahan Mahamandal limited, the research shows that Safety, Comfortability and Punctuality can be used effectively to assess the reliability of the system. Firstly, after analyzing the safety factor it can be observed that out of the total bus fleet in PMC, about $62 \%$ of the buses are above the age limit of 8 years. As a result, the chances of bus breakdown and accident increases. Also, certain safety tools and equipment which are necessary when it comes to bus safety were missing in several buses. As a result, these buses are unsafe to drive and unfit to commute.

In Punctuality factor, Scheduled and actual Journey time was compared, further it is concluded that the punctuality on all the four routes is uneven, also while reaching the destination, it was observed that bus skipped the Bus stops on daily basis, which severely affect the reliability of the bus. Also, as the route length increased, bus service was found to be unreliable for all the mentioned performance parameters.

In comfortability factor, the passenger accumulation, the load factor, and the speed of the bus was studied and the aim was to examine the effects of passenger load factor on the reliability of bus. It was observed that long route buses have the high load factor as compared to short route buses. The load factor was exceeding beyond the average comfortability factor of $40 \%$.

The analysis presented here is limited to a set of data actually collected over a period of 4 days. Although limited, this analysis shows a potential amount of information about bus operations in Pune and after analyzing the above-mentioned performance parameters, it can be concluded that the Bus Transport System in Pune Municipal Corporation is Unreliable.

\section{Recommendations}

1) To improve the safety of bus, certain safety tools like First Aid Kit/Box, Fire Extinguisher, Helpline no. various organizations, should be provided on the bus. Sufficient Holding bars, and Arm holder should be fixed in all the buses for the passenger standing and Old/broken seat should be installed or replaced with the new seat for passenger comfort. Emergency exit windows must be fixed as most of them are either broken or jammed. Broken windows to be replaced immediately which will avoid any further injuries to passengers commuting.

2) As many as $\mathbf{6 2 \%}$ of the buses of PMPML are above the age limit of 8 years set by Central Institute of Road Transport. These buses should be either scrapped or replaced to avoid further breakdown rate and accidents. Taking into consideration the sustainability factor, Electric buses or CNG buses should be introduced which will decrease the pollution level as well.

3) Route Restructuring is necessary so that all the routes are evenly distributed and flourished in every area of Pune Municipal Corporation and it will improve the accessibility of Bus Transport System.

4) The transportation network should be restructured from destination oriented to direction oriented with a simplified route structure and reduced waiting time.

5) Decreasing the route length or dividing the long routes in two parts as short routes cut down the number of intersections, are efficient, less time consuming, and are less prone to traffic.

\section{References}

[1] Yin, Y. L. (2004). A simulation-based reliability assessment approach for congested transit network. Journal of advanced transportation, 38(1), , 27-44.M. Young, The Technical Writer's Handbook. Mill Valley, CA: University Science, 1989.

[2] Kittelson\& Associates, U. S. (2003). Federal Transit Administration, Transit Cooperative Research Program

\section{Volume 6 Issue 12, December 2017}


\& Transit Development Corporation. Transit Capacity and quality of service manual (No. 100) Transportation Research Board.

[3] Strathman, J. G. (1993). Empirical analysis of bus transit on-time performance. Transportation Research Part A: Policy and Practice, 27(2), 93-100.

[4] Abkowitz M.D., \&. E. (1983). Factors affecting running time in transit routes. Transportation Research Part A: General, 17(2), 107-113.

[5] (n.d.). Central Institue of Road Transport.

[6] (2008). City Development Plan Pune.

[7] (2008). Comprehensive Mobility Plan Pune.

[8] Figliozzi, M. A. (2010). Transit Bus Fleet Age and Replacement Type Optimization. Portland: Transportation Research and Education Center (TREC).

[9] (June 2010). Public Transport in Netherlands. Ministry of Transport, Public works and Water Management.

[10] (n.d.). Pune Mahanagar Parivahan Mahamandal Limited.

[11] (n.d.). Pune Municipal Corporation.

[12] Qizhi, L. U. (2006). A Matlab simulation method for evaluation of travel time reliability of public transportation system. Urban Transport of China, 4, 016.

[13] Ronghui Lui, S. S. (n.d.). Modelling Urban Bus Service and passenger relaibility. Leeds, Uk: Institute for transport studies.

[14] Stephen Arhin, E. C. (November, 2013). Evaluation of Bus transit reliability in District of Columbia.

\section{Author Profile}

Ninad Chandrayan received the B.Plan degrees in Town Planning from Amity School of Architecture and Planning in 2017. 